\title{
Börülcede Bazı Fiziksel ve Teknolojik Özelliklerin Belirlenmesi
}

\author{
Ruziye KARAMAN ID 1*, Cengiz TÜRKAY ID 1 \\ ${ }^{1}$ Isparta Uygulamalı Bilimler Üniversitesi, Ziraat Fakültesi, Tarla Bitkileri Bölümü, Isparta, Türkiye \\ Geliş Tarihi (Received): 04.10.2021, Kabul Tarihi (Accepted): 22.11.2021 \\ $\square$ Sorumlu Yazar (Corresponding author*): ruziyekaraman@isparta.edu.tr \\ (C) +902462186256 등 +902462146399
}

\section{ÖZ}

Çalışmada, ülkemizin farklı bölgelerinden temin edilen börülce genotip ve çeşitlerinin fiziksel ve teknolojik özelliklerinin belirlenmesi amaçlanmıştır. Araştırmada, Türkiye'nin farklı bölgelerinden temin edilen 5 genotip [Adana (B1), İzmir (B2), Mersin (B3), Mersin/Mut (B4) ve Isparta (B5)] ve 2 adet tescilli çeşit (Amazon ve Sırma) kullanılmıştır. Çalışmada yıllar x genotip interaksiyonu baklada tane sayısı, tohum uzunluğu ve hacim özelliklerinde istatistiki olarak önemli bulunmuştur. Çalışmada baklada tane sayısı 6.37-8.77 adet, bakla uzunluğu 13.18-16.69 cm, bakla genişliği 7.30$9.31 \mathrm{~mm}$, tohum uzunluğu $8.35-10.14 \mathrm{~mm}$, tohum genişliği $6.28-7.50 \mathrm{~mm}$, kuru ağırlığı 13.24-22.35 g, yaş ağırlığı 25.04-46.02 g, şişme indeksi 2.09-2.70, geometrik ortalama çapları 6.51-7.54 mm, küresellik değeri 0.73-0.79, tohum hacmi 155.12-233.67 mm ${ }^{3}$ yüzey alanı değerleri 120.58-172.23 mm² arasında değişim göstermiştir. Genotip ve çeşitlerin iki yıl ortalaması değerlendirildiğinde genel olarak incelenen özelliklerde B1 genotipi ile Sırma çeşidi ön plana çıkmaktadır. Sonuç olarak incelenen özellikler mekanizasyon ve tüketicilerin satın almada tercihinde önem arz etmesi sebebiyle B1 genotipinin (Adana) ıslah işlemlerinde ön plana çıkacağı öngörülmektedir.

Keywords: Börülce, fiziksel özellikler, genotip, teknolojik özellikler, tohum ve bakla karakterizasyonu

\section{Determination of Some Physical and Technological Characteristics on Cowpea}

\begin{abstract}
In the study, it was aimed to determine physical and technological characteristics of cowpea genotypes and varieties obtained from different regions of our country. In the research, 5 genotypes obtained from different regions of Turkey [Adana (B1), Izmir (B2), Mersin (B3), Mersin/Mut (B4) and Isparta (B5)] and 2 registered cultivars (Amazon and Sirma) were used. In the study, years $x$ genotype interaction was found to be statistically significant in the number of seeds per pod, seed length and volume characteristics. In the study, it is varied between that number of seeds per pod was 6.37-8.77, pod length 13.18-16.69 cm, pod width 7.30-9.31 mm, seed length 8.35-10.14 mm, seed width 6.28-7.50 $\mathrm{mm}$, dry weight 13.24-22.35 g, wet weight 25.04-46.02 g, swelling index 2.09-2.70, geometric mean diameter 6.51$7.54 \mathrm{~mm}$, sphericity value $0.73-0.79$, seed volume $155.12-233.67 \mathrm{~mm}^{3}$ surface area values $120.58-172.23 \mathrm{~mm}^{2}$. When two-year average of genotypes and cultivars is evaluated, B1 genotype and Sirma cultivar come to fore in the generally examined characteristics. As a result, it is predicted that B1 genotype (Adana) will come to forefront in breeding processes due to importance of mechanization and consumers' choice in purchasing.
\end{abstract}

Anahtar Kelimeler: Cowpea, physical characteristics, genotype, technological characteristics, seed and pod characterization 


\section{GíRiş}

Insan beslenmesinde önemli bir bitkisel protein ve vitamin kaynağı olan börülcenin (Vigna unguiculata L. Walp) besleyici değeri yüksek genç yaprakları ve yeşil baklaları sebze olarak tüketilebilmektedir (Alayande ve ark., 2012; Avanza ve ark., 2013). Bunların yanında, yeşil gübre, hayvan yemi ve toprak verimliliğinin geri kazanılmasında da kullanılabilen, kuraklığa dayanıklı sıcak mevsim baklagil bitkisidir (Rivas ve ark., 2016). Dünya genelinde börülce üretimi 8.9 milyon ton olup, bu üretimin büyük bir çoğunluğunu Afrika ülkeleri oluşturmaktadır. Ülkemizde ise, ekim alanı 13 bin ha ve üretim miktarı 1.4 bin tondur (FAO, 2019). Börülce tarımı, çoğunlukla ülkemizin Ege, Akdeniz ve Batı Marmara bölgelerinde yapılmaktadır (TUIK, 2019).

Ülkemizde börülce yetiştiriciliği uzun yıllardan beri yapılmasıyla birlikte özellikle doğal ve insan eliyle yapılan seleksiyonlar çeşitli börülce populasyonlarının oluşmasını sağlamıştır (Binici ve Bozalkafa, 2020). Nitekim, bu popülasyonlar arasında varyabilite, bakla ve tohum morfolojisi gibi agronomik özelliklerde çeşitli varyasyonlar bulunmaktadır (Vural ve ark., 2000). Kır ve ark. (2015), yerel börülce populasyonlarının morfolojik ve fiziksel özellikleri arasında yüksek varyasyonlar olduğunu ifade etmiş ve tohum boyunun $6.7-11.5 \mathrm{~mm}$, genişliğinin 4.9-7.4 mm, kalınlığının 3-5 mm ve baklada tane sayısının 6.0-15.0 arasında değişen değerlere sahip olduğunu ifade etmişlerdir. Yetiştiriciliğinin yapıldığı bölgenin çevre şartlarına uyum sağlayabilecek, verim ve kalite parametreleri bakımından daha üstün performans gösteren börülce genotiplerinin geliştirilip üretime kazandırılması ülkemiz açısından büyük önem arz etmektedir.

Tarımsal ürünlerin fiziksel özellikleri; ekim ve dikimi, sınıflandırılması, hasat ve harmanı, işlenmesi, iletimi ve taşınması ile depolanmasında önemi rol oynamaktadır (Özlü ve Güner, 2016). Tohumların fiziksel (şekil ve boyut) özellikleri, çimlenme ve çimlenme sonrası oluşan bitkinin sağığı ile gelişiminde oldukça etkilidir (Salisbury ve Ross, 1992; Dumanoğlu ve ark., 2019). Şekil ve boyut değerleri yüksek olan tohumların tane irilikleri ve bin tane ağırlıkları fazla olmaktadır. Kabaş ve ark. (2007), börülce tohumlarının geometrik ortalama çapını $7.16 \mathrm{~mm}$, küresellik değerini 0.77 , bin tane ağırığını 20.50 ve tohum hacmini $180 \mathrm{~mm}^{3}$ olduğunu ifade etmişlerdir. Kınacı ve ark. (2008), tohum ağırlığı arttıkça irilikleri de artmakta olduğunu, özellikle iri taneler pazarlamada büyük önem taşıdığını ifade etmişlerdir. Örneğin, konserve için büyük tohumlu çeşitler tercih edilmektedir. Bu sebeple yüksek miktarda pişmiş tane ağırığı elde etmek için daha az miktarda fasulye intiyaç olacağını ifade etmektedir (Henshaw 2008). Diğer taraftan, yemeklik tane baklagillerin teknolojik özellikleri tüketiciler için oldukça önem arz etmektedir. Su almış tohumların şişme kapasitesi ve indeksi, tohum iriliği ile tohum hacmi gibi özellikler pişme süresi ile ilişkili olup, baklagillerin en önemli seleksiyon kriterleridir. Ayrıca, şişme özellikleri hızlı ve fazla olan tohumlar gıda işleme endüstrisinde aranan özelliklerden birisidir (Karaman, 2019). Nitekim Verma ve ark. (2019), börülce çeşitlerinin şişme indeksi değerlerini 1.40-1.86 arasında değişim gösterdiği ve yüz tane ağırığı yüksek olan genotiplerin şişme indeksi değerlerinin de yüksek olduğunu ifade etmişlerdir. Tohumların fiziksel, teknolojik ve kalite özellikleri, çeşitlere göre değişmekle birlikte, yetiştirildiği bölgenin çevre şartları da oldukça etkili olabilmektedir. Günümüzde tarımsal üretimi artırmak için genetik kaynakların toplanması, tanımlanması, saklanması ve kullanımı giderek önem kazanmaktadır. Bu çalışmada, ülkemizin farklı bölgelerinden temin edilen börülce genotip ve çeşitlerinin fiziksel ve teknolojik özelliklerinin belirlenmesi amaçlanmıştır.

\section{MATERYAL VE YÖNTEM}

Çalışma 2019 ve 2020 yıllarında Isparta Uygulamalı Bilimler Üniversitesi Ziraat Fakültesi deneme arazilerinde yürütülmüştür. Araştırmada, Türkiye'nin farklı bölgelerinden temin edilen 5 genotip [Adana (B1), İzmir (B2), Mersin (B3), Mersin/Mut (B4) ve Isparta (B5)] ve 2 adet tescilli çeşit (Amazon ve Sırma) kullanılmıştır. Genotipler, yörelerine yapılan survey çalışmalarından, tescilli çeşitler ise, Ondokuz Mayıs Üniversitesi Ziraat Fakültesi'nden temin edilmiştir.

Araştırmanın yapıldığı arazinin toprak özellikleri Şenol ve ark. (2020), tarafından orta ve ağır bünyeli, hafif alkali, EC içeriği oldukça düşük $\left(0.20 \mathrm{dS} \mathrm{m}^{-1}\right)$ ve organik madde miktarının da düşük olduğu tespit edilmiştir. Ayrıca araştırmacılar, arazinin azot içeriğini yeterli $(\% 0.10)$ fosfor içeriğinin orta $\left(7.96 \mathrm{mg} \mathrm{kg}^{-1}\right)$, potasyum içeriğinin ise, oldukça yüksek $\left(1.60 \mathrm{mg} \mathrm{kg}^{-1}\right)$ seviyede olduğunu bildirmişlerdir. Çalışmanın yapıldığı aylarda, 1. yıl ortalama sıcaklık $19.7^{\circ} \mathrm{C}$; toplam yağış 205.4 $\mathrm{mm}$; 2 . yılda ise ortalama sıcaklık $20.3^{\circ} \mathrm{C}$; toplam yağış $235.3 \mathrm{~mm}$ olarak rapor edilmiştir. Bu değerler ise uzun yıl verilerine göre sıcaklık yönünden $\left(20.2^{\circ} \mathrm{C}\right)$ ilk yıl $0.5^{\circ} \mathrm{C}$ daha düşük iken, ikinci yıl ise, uzun yıllar ortalama sıcaklık ile neredeyse aynı seviyededir.

Çalışma, Tesadüf Blokları deneme deseninde 3 tekerrürlü olarak kurulmuştur. Her parsel, 3 m uzunluğunda ve 6 sıradan oluşmuştur. Ekim, sıra arası ve üzeri $40 \times 15 \mathrm{~cm}$ olacak şekilde $5-7 \mathrm{~cm}$ derinliğe ekilmiştir. Ekim ilk yıl 3 Mayıs 2019 tarihinde, ikinci yıl ise $27 \mathrm{Ni}-$ san 2020 tarihinde elle yapılmıştır. Ekim sırasında 6 kg 
$\mathrm{da}^{-1} \mathrm{~N}$ ve $6 \mathrm{~kg} \mathrm{da}^{-1} \mathrm{P}_{2} \mathrm{O}_{5}$ olacak şekilde gübreleme yapılmıştır. Bitkilerin su intiyacı toprağın nem durumu ve iklim koşulları göz önünde bulundurularak damla sulama ile karşılanmıştır. Yabancı otlar mekanik olarak el ve çapalama ile kontrol altına alınmıştır. Çeşit ve genotiplerin olgunlaşması ile birlikte parsellerden tesadüfen seçilen 100 adet baklada, baklada tane sayısı, bakla ve tohum boyutları belirlenmiştir. Bakla ve tohumların boyutları (en ve boy) $0.01 \mathrm{~mm}$ hassasiyetindeki dijital kumpas kullanılarak tespit edilmiştir. Kuru ağırlık, yaş ağırlık ve şişme indeksi özellikleri Tarım ve Orman Bakanlığı Tohumluk Tescil ve Sertifikasyon Merkezi Müdürlüğü'nün Tarımsal Değerleri Ölçme Denemeleri Teknik Talimatında belirtildiği ölçüde yapılmıştır (TTSM, 2001). Geometrik ortalama çap ve küresellik değerleri 1 ve 2 nolu eşitlik kullanılarak belirlenmiştir (Kiani Deh Kiani ve ark., 2008; Davies, 2010; Moses ve Zibokere, 2011). Tohumların yüzey alanı ve hacimlerinin belirlenmesinde ise 3 ve 4 nolu eşitlikler kullanılmıştır (Bart-Plange ve ark., 2012; TwumasiAnkra, 2015).

$$
\begin{aligned}
& D_{g}=(L W T)^{1 / 3} \\
& \left.\Phi=\left((L W T)^{1 / 3}\right) / L\right)
\end{aligned}
$$

Eşitliklerde kullanılan $D_{g}$ : Geometrik ortalama çap $(\mathrm{mm}), \Phi$ : küresellik değeri, L: tohum uzunluğu $(\mathrm{mm})$,
W: tohum genişliği $(\mathrm{mm})$ ve $\mathrm{T}$ : tohum kalınlığını $(\mathrm{mm})$ ifade etmektedir.

$$
\begin{aligned}
& S=\pi\left(D_{g}{ }^{2}\right) \\
& V=\pi / 6\left(D_{g}{ }^{3}\right)
\end{aligned}
$$

Eşitlikteki S: yüzey alanını $\left(\mathrm{mm}^{2}\right)$, V: tohum hacmini $\left(\mathrm{mm}^{3}\right)$ ifade etmektedir.

Çalışmada incelenen özelliklere ait veriler Tesadüf Blokları Deneme desenine uygun olarak MINITAB paket programından yararlanarak varyans analizine tabi tutulmuş, ortalamalar arasındaki farklılıklar Tukey testine göre belirlenmiştir.

\section{BULGULAR VE TARTIŞMA}

Börülce çeşit ve genotiplerinin incelenen fiziksel ve teknolojik özelliklerine ilişkin varyans analiz sonuçlarına göre incelenen tüm özelliklerde genotipler, bakla genişliği, şişme indeksi, yüzey alanı, bakla ve tohum uzunluğu, geometrik ortalama çap ve hacim özelliklerinde yıllar arasındaki farklılıkları istatistiki açıdan önemli olarak belirlenmiştir. Diğer taraftan baklada tane sayısı, tohum uzunluğu ve hacim özellikleri için de

\begin{tabular}{|c|c|c|c|c|c|c|c|}
\hline V.K. & S.D. & $\begin{array}{l}\text { Baklada } \\
\text { Tane Sayısı }\end{array}$ & $\begin{array}{l}\text { Bakla } \\
\text { Uzunluğu }\end{array}$ & Bakla Genişliği & $\begin{array}{l}\text { Tohum } \\
\text { uzunluğu }\end{array}$ & $\begin{array}{l}\text { Tohum } \\
\text { Genişliği }\end{array}$ & $\begin{array}{l}\text { Kuru } \\
\text { Ağırlık }{ }^{1} \\
\end{array}$ \\
\hline YII(A) & 1 & $1.86 \mathrm{~ns}$ & $22.30^{* \star}$ & $5.12^{*}$ & $37.94^{\star \star}$ & $2.82 \mathrm{~ns}$ & $2.37 n s$ \\
\hline Genotip(B) & 6 & $10.11^{* *}$ & $22.07^{\star *}$ & $10.66^{* *}$ & $35.30^{* *}$ & $2.82^{*}$ & $32.41^{* *}$ \\
\hline$A \times B$ & 6 & $2.53^{*}$ & $1.97 \mathrm{~ns}$ & $0.29 \mathrm{~ns}$ & $4.24^{\star *}$ & $0.58 \mathrm{~ns}$ & $0.73 \mathrm{~ns}$ \\
\hline C.V.(\%) & & 9.96 & 3.82 & 5.64 & 2.73 & 8.53 & 6.65 \\
\hline V.K. & S.D. & Yaş Ağırlık & $\begin{array}{l}\text { Şişme In- } \\
\text { deksi }\end{array}$ & $\begin{array}{l}\text { Geometrik Or- } \\
\text { talama Çap }\end{array}$ & Küresellik & Hacim & $\begin{array}{l}\text { Yüzey } \\
\text { Alanı }\end{array}$ \\
\hline YII(A) & 1 & $0.66 \mathrm{~ns}$ & $4.37^{\star}$ & $18.00^{* *}$ & $0.30 \mathrm{~ns}$ & $48.57^{* *}$ & $0.66^{*}$ \\
\hline Genotip(B) & 6 & $100.16^{\star *}$ & $47.57^{\star \star}$ & $11.05^{\star *}$ & $5.37^{\star *}$ & $160.64^{\star \star}$ & $100.16^{\star *}$ \\
\hline$A \times B$ & 6 & $0.50 \mathrm{~ns}$ & $1.03 \mathrm{~ns}$ & $1.39 \mathrm{~ns}$ & $0.89 \mathrm{~ns}$ & $4.58^{\star \star}$ & $0.50 \mathrm{~ns}$ \\
\hline $\mathrm{CV}(\%)$ & & 4.37 & 3.57 & 3.45 & 3.40 & 2.5 & 4.37 \\
\hline
\end{tabular}
yıl $x$ genotip interaksiyonunun önemli olduğu tespit edilmiştir (Tablo 1).

Tablo 1.Börülce çeşit ve genotiplerinin incelenen fiziksel ve teknolojik özelliklerine ilişkin varyans analiz sonuçları

${ }^{*} \mathrm{P}<0.05,{ }^{* *} \mathrm{P}<0.01,{ }^{1}$ : Özelliklerin F değerleri, V.K.: Varyasyon Kaynakları; S.D.: Serbestlik Derecesi; CV: Varyasyon Katsayısı

Börülcede, tohum verimini belirleyen en önemli bitkisel özelliklerden birisi baklada tane sayısıdır. İki yıl ortalamalarına göre en yüksek baklada tane sayısı Amazon çeşidi (8.77 adet) ile B1 (8.33) genotipinde tespit edilmiştir. En düşük baklada tane sayısı ise, sırasıyla B2 (6.54 adet), B4 (6.37 adet) ve B5 (6.57 adet) genotiplerinde saptanmıştır. Her iki yılda da en yüksek baklada tane sayısı Amazon çeşidinde belirlenmiş ve Amazon çeşidini B1 genotipi takip etmiştir. 2019 yllında en düşük baklada tane sayısı B2, B4, B5 genotiplerinde; 2020 yılında ise B2, B3, B4, B5 genotipleri ile Sırma çeşidinde belirlenmiştir (Tablo 2). Baklada tane sayısı, bitkide bakla sayısı ve bakla uzunluğunun seleksiyon için en önemli özelliklerden birisidir (Ombakho ve Tyagi, 1987). Pekşen ve Artık (2004), börülce genotiplerinin baklada tane sayısının 9.27-12.29 adet arasında değiştiğini, tane verimine baklada tane sayısının doğrudan etki ettiğini ifade etmişlerdir. Baklada tohum sayısı, aynı zamanda iklim, toprak ve genotiplerin genetik yapısına bağlı olarak değişebilmektedir. Nitekim, Başaran ve ark. (2011), Doğu Karadeniz'de börülce genotiplerinin baklada tane sayısının 
9.9 adet, Sert ve Ceyhan (2012), Hatay'da 5.00-5.11, Öztürk (2010), Ordu'da 7.1-9.7 adet, Kır ve ark. (2015), İzmir'de 6.0-15.0 adet arasında değişim gösterdiklerini bildirmişlerdir.

Börülce genotip ve çeşitlerinin iki yıl ortalamalarına göre bakla uzunluğu $13.18-16.69 \mathrm{~cm}$ arasında değişim göstermiş, en yüksek bakla uzunluğu Amazon çeşidinde, en kısa ise B5 genotipinde tespit edilmiştir. Bununla birlikte yıllar arasında önemli farklılıklar ortaya çıkmış, $2019(14.47 \mathrm{~cm})$ yılındaki bakla boyu ortalaması $2020(15.29 \mathrm{~cm})$ yılına göre daha düşük olduğu belirlenmiştir (Tablo 2). Bakla uzunluğu, baklada tane sayısı ilişkili olup, tohum verimini etkilemektedir (Khan ve ark., 2010). Nitekim çalışmada da, baklada tane sayısı ile fazla olan genotip ve çeşitlerin bakla boyu daha uzun olduğu görülmektedir. Bu konu üzerinde araştırmalar yapan Pekşen ve Artık (2004) börülce genotiplerinin bakla uzunluğunu $12.62-16.06 \mathrm{~cm}$, Futuless ve Bake (2010) 13.23-20.03 cm, Öztokat ve Demir (2010), 13.35-38.81 cm, Khan ve ark. (2010), 10-38 $\mathrm{cm}$ arasında değişim gösterdiği bildirmişlerdir. Araştırma sonuçlarına göre bakla uzunluğunun bazı literatürlerle uyum içerisinde olmaması, çevresel ve tarımsal uygulamalarının etkisinin yanında, çalışmada kullanımış olan genotiplerin genetik yapılarından kaynaklanabilmektedir.
Bakla genişliği bakımından genotip ve çeşitler arasında önemli farklııklar ortaya çıkmıştır. İki yıl ortalamalarına göre bakla genişliği 7.30-9.31 mm arasında değişim göstermiştir. En yüksek bakla genişliği Sırma çeşidinde belirlenirken, B1, B2, B3 ve B4 genotipleri ile Sırma çeşidi istatistiki olarak aynı grupta yer almışlardır. En düşük baklada tane sayısı ise B5 genotipinde belirlenmiştir. Yıllar arasındaki farklılık istatistiki yönden önemsiz bulunmuş olup, ikinci yıl $(8.74 \mathrm{~mm})$ birinci $(8.40 \mathrm{~mm})$ yıla göre baklalar daha yüksek bakla genişliğine sahip olmuştur (Tablo 2). Mendonça ve ark. (2018), börülce genotiplerinde inceledikleri özellikler arasındaki genetik ilerleme ve korelasyona ilişkin sonuçlarda, bakla uzunluğu, bakla genişliği, ana dal sayısı ve çiçeklenme süresi özellikleri daha yüksek tane verimine sahip yeni çeşitler elde etmek ve ebeveyn seçiminde dikkate alınması gerektiği ifade etmişlerdir. Ayrıca Bozalkafa ve Sürmeli (2019), börülce genotiplerinde bakla genişliği bakımından yüksek varyabilite belirlemişler ve börülcenin taze olarak tüketiminde daha geniş baklaların tercih edildiğini ifade etmişlerdir. Çalışmada börülce genotip ve çeşitlerinin bakla genişliği bakımından elde edilen sonuçlar benzer konularla yapılan araştırma sonuçlarıile paralellik göstermektedir (Ünlü ve Padem, 2005; Futuless ve Bake, 2010; Öztürk, 2010; Bozalkafa ve Sürmeli, 2019).

Tablo 2. Börülce çeşit ve genotiplerinin baklada tane sayısı, bakla uzunluğu ve bakla genişliğiilişkin ortalama değerler

\begin{tabular}{|c|c|c|c|c|c|c|c|c|c|}
\hline \multirow{2}{*}{$\begin{array}{l}\text { Geno- } \\
\text { tip/Çe- } \\
\text { şitler }\end{array}$} & \multicolumn{3}{|c|}{ Baklada Tane Sayısı (adet) } & \multicolumn{3}{|c|}{ Bakla uzunluğu (cm) } & \multicolumn{3}{|c|}{ Bakla genişliği (mm) } \\
\hline & 2019 & 2020 & Ort. & 2019 & 2020 & Ort. & 2019 & 2020 & Ort. \\
\hline B1 & $8.85 a b$ & $7.80 a b$ & $8.33 a b$ & 14.58 & 16.56 & $15.57 \mathrm{~b}$ & 8.60 & 9.04 & $8.82 a b^{*}$ \\
\hline B2 & $6.20 \mathrm{c}$ & $6.89 \mathrm{~b}$ & $6.54 \mathrm{~d}$ & 14.47 & 15.20 & $14.83 \mathrm{bc}$ & 8.56 & 8.93 & $8.74 \mathrm{ab}$ \\
\hline B3 & $8.76 a b$ & $7.00 \mathrm{~b}$ & $7.88 \mathrm{bc}$ & 14.53 & 15.47 & $15.00 \mathrm{bc}$ & 8.33 & 8.58 & $8.46 \mathrm{ab}$ \\
\hline B4 & $6.04 \mathrm{c}$ & $6.71 \mathrm{~b}$ & $6.37 \mathrm{~d}$ & 13.80 & 14.68 & $14.24 \mathrm{c}$ & 8.71 & 9.29 & $9.00 \mathrm{ab}$ \\
\hline B5 & $6.31 \mathrm{c}$ & $6.82 \mathrm{~b}$ & $6.57 \mathrm{~d}$ & 12.93 & 13.42 & $13.18 \mathrm{~d}$ & 7.21 & 7.39 & $7.30 \mathrm{c}$ \\
\hline Amazon & $9.02 \mathrm{a}$ & $8.52 \mathrm{a}$ & $8.77 \mathrm{a}$ & 16.79 & 16.59 & $16.69 \mathrm{a}$ & 8.38 & 8.37 & $8.38 b$ \\
\hline Sırma & $7.60 \mathrm{~b}$ & $6.87 \mathrm{~b}$ & $7.24 \mathrm{~cd}$ & 14.15 & 15.14 & $14.65 \mathrm{bc}$ & 9.04 & 9.58 & $9.31 \mathrm{a}$ \\
\hline Ort. & 7.54 & 7.23 & & $14.47 \mathrm{~b}$ & $15.29 \mathrm{a}$ & & 8.40 & 8.74 & \\
\hline
\end{tabular}

B1: Adana, B2:İmir, B3:Mersin, B4:Mersin/Mut, B5:Isparta

*Aynı harflere sahip ortalamalar arasında istatistiksel farklılık bulunmamaktadır

Araştırmada kullanılan börülce çeşit ve genotiplerinin ortalama tohum uzunlukları 8.35-10.14 $\mathrm{mm}$ arasında değişim göstermiş olup, en uzun tohum uzunlukları sırasıyla B1, B2 (10.09 $\mathrm{mm})$ ve B4 $(9.89 \mathrm{~mm})$ genotiplerinde tespit edilmiştir. En kısa tohum uzunluğu ise, B5 genotipinde belirlenmiştir. Tohum boyu yıllara göre farklılıklar göstermiş olup, ikinci yıl birinci yıla göre daha uzun tohum boyuna sahip olmuştur. Her iki yılda da en yüksek tohum uzunluğu B1, B2 ve B4 genotiplerinde, en kısa tohum uzunluğu ise B5 genotipinde belirlenmiştir. Ayrıca çalışmada börülce genotiplerinin (B5 genotipi hariç) tohum boyları tescilli çeşitlerden daha uzun olduğu tespit edilmiştir (Tablo 3). Tohum uzunluğu, genotip ve çeşitlerin genetik yapısına, uygulanan kültürel işlemler ile çevre şartlarına bağlı olarak değişiklik gösterebilmektedir. Nitekim, tohum uzunluğunu Peşken ve ark. (2000), 5.64-10.04 mm, Öztürk (2010), 8.0-10.6 mm, Sürmeli (2017), 7.8-11.1 mm, Binici ve Bozalkafa (2020), 7.98-12.28 mm arasında değişim gösterdiğini ifade etmiştir. Çalışmadan elde edilen veriler daha önce yapılan araştırmalarla uyum içerisindedir. 
Börülce genotipve çeşitlerin ortalama tohum genişliği 6.28-7.50 mm arasında değişim göstermiş, en yüksek tohum genişliği B1 genotipinde, en düşük ise B5 genotipinde tespit edilmiştir. Ayrıca ikinci yıl $(6.92 \mathrm{~mm})$ birinci yıla $(6.62 \mathrm{~mm})$ göre daha yüksek tohum genişliğine sahip olmuştur (Tablo 3). Ajayi ve ark. (2014), börülce genotiplerinin ortalama tohum genişliklerini 3.58 $\mathrm{mm}$ olarak belirlemiş ve tohum genişliğinin kalıtım derecesini (\%98.82), genotipik (44.34) ve fenotipik (49.48) varyasyon katsayısının yüksek olduğunu ifade etmişlerdir. Bununla birlikte tohum genişliğini Pekşen ve ark. (2000), 3.86-6.33 mm, Kabaş ve ark. (2007), $6.55 \mathrm{~mm}$, Öztürk (2010), 5.16-7.63 mm, Molosiwa ve ark. (2016), 5.72 ile $7.0 \mathrm{~mm}$ arasında değişim gösterdiğini bildirmişlerdir. İncelenen literatür çalışmaları sonucunda çalışmadaki bulgular benzerlik göstermektedir.

Tane iriliği verimi etkileyen önemli bir kriter olmasıyla beraber, büyük taneli çeşitler pazar değeri bakımından da önem arz etmektedir (Aydoğan ve ark., 2020). Çaış̧mada kullanılan börülce çeşit ve genotiplerinin kuru ağırlıkları önemli farklılıklar göstermiştir. Nitekim, genotip ve çeşitlerin kuru ağırlıkları 13.24-22.35 g arasında değişim göstermiş, en düşük kuru ağırlık B5 genotipinde tespit edilmiştir. En yüksek kuru ağırlığa ise Sırma çeşidi sahip olmuş, B5 genotipi dışındaki çeşit ve genotipler Sırma çeşidi ile aynı istatistiki grupta yer almışlardır. Genotip ve çeşitlerin kuru ağırlık değerleri yıllara göre farklılık göstermemiş olup, 2019 yılı(20.40 g), 2020 yılına (19.77) göre daha yüksek kuru ağırlığa sahip olmuştur (Tablo 3).Börülcede kuru ağırlık özelliği genotip ve çeşitlerinin tesadüfen seçilen yüz adet tanenin $g$ olarak ifade edilmesidir. Yemeklik tane baklagillerde tane iriliğinin göstergesi olarak kuru ağırlık veya yüz tane ağırlığı kullanılabilmektedir. Genotiplerin yüz tane ağırlığı üzerine etkisi yüksek olmasıyla beraber çevre şartlarından da önemli ölçüde etkilenmektedir (Şehirali ve ark., 1994). Börülcede yüz tane ağırIığı, 10.0-30.0 g arasında değişim gösterebilmektedir (Pekşen ve Artık, 2004; Öztürk, 2010; Başaran ve ark., 2011; Goenaga ve ark., 2013). Elde edilen veriler ile incelenen literatür çalışmaları uyum içerisindedir.

Tablo 3. Börülce çeşit ve genotiplerinin tohum uzunluğu, tohum genişliği ve kuru ağırlığına ilişkin ortalama değerler

\begin{tabular}{cccccccccc}
\hline Genotip/ & \multicolumn{2}{c}{ Tohum uzunluğu $\mathbf{( m m )}$} & \multicolumn{2}{c}{ Tohum genişliği $(\mathbf{m m})$} & \multicolumn{3}{c}{ Kuru Ağırlık (g) } \\
\cline { 2 - 10 } Çeşitler & $\mathbf{2 0 1 9}$ & $\mathbf{2 0 2 0}$ & Ort. & $\mathbf{2 0 1 9}$ & $\mathbf{2 0 2 0}$ & Ort. & $\mathbf{2 0 1 9}$ & $\mathbf{2 0 2 0}$ & Ort. \\
\hline B1 & $9.77 \mathrm{ab}$ & $10.51 \mathrm{a}$ & $10.14 \mathrm{a}$ & 7.08 & 7.91 & 7.50 & 22.21 & 21.67 & $21.94 \mathrm{a}^{*}$ \\
B2 & $9.95 \mathrm{a}$ & $10.23 \mathrm{a}$ & $10.09 \mathrm{a}$ & 6.59 & 6.87 & 6.73 & 20.52 & 20.67 & $20.59 \mathrm{a}$ \\
B3 & $9.35 \mathrm{bc}$ & $9.73 \mathrm{~b}$ & $9.54 \mathrm{bc}$ & 6.43 & 6.50 & 6.47 & 20.23 & 20.59 & $20.41 \mathrm{a}$ \\
B4 & $9.53 \mathrm{ab}$ & $10.25 \mathrm{a}$ & $9.89 \mathrm{ab}$ & 6.46 & 6.72 & 6.59 & 21.79 & 20.80 & $21.29 \mathrm{a}$ \\
B5 & $7.73 \mathrm{~d}$ & $8.97 \mathrm{~d}$ & $8.35 \mathrm{~d}$ & 6.43 & 6.13 & 6.28 & 14.46 & 12.02 & $13.24 \mathrm{~b}$ \\
Amazon & $9.45 \mathrm{bc}$ & $9.39 \mathrm{bc}$ & $9.42 \mathrm{c}$ & 6.64 & 7.03 & 6.83 & 20.87 & 20.70 & $20.79 \mathrm{a}$ \\
Sırma & $9.04 \mathrm{C}$ & $9.21 \mathrm{~cd}$ & $9.13 \mathrm{c}$ & 6.70 & 7.26 & 6.98 & 22.74 & 21.95 & $22.35 \mathrm{a}$ \\
\hline Ort. & $9.26 \mathrm{~b}$ & $9.76 \mathrm{a}$ & & 6.62 & 6.92 & & 20.40 & 19.77 & \\
\hline
\end{tabular}

B1: Adana, B2:İzmir, B3:Mersin, B4:Mersin/Mut, B5:Isparta

*Aynı harflere sahip ortalamalar arasında istatistiksel farklılık bulunmamaktadır

Börülce genotip ve çeşitlerinin ortalama yaş ağırlığı, 25.04-46.02 g arasında değişim göstermiş, en düşük yaş ağırlık B5 genotipinde tespit edilmiştir. En yüksek yaş ağırlık ise Sırma çeşidinde tespit edilmiş ve B5 genotipi dışındaki çeşit ile genotipler Sırma çeşidiyle aynı istatistiki grupta yer almışlardır. Yıllar arasında önemli bir farklılık olmasa da, 2019 yılındaki yaş ağırlık 2020 yılına göre daha yüksek olduğu tespit edilmiştir. Ayrıca, çalışmada börülce genotip ve çeşitlerinin yaş ağırıkları, kuru ağırlık değerleriyle paralellik göstermiştir (Tablo 4). Nitekim, yaş ağırık değerleri tane iriliklerine göre değişim göstermekte olup, tane iriliği arttıkça su alma kapasitesi de artmakta dolasıyla yaş ağırlık değerleri de yüksek olmaktadır (Çalışkan ve ark., 2018). Buna ek olarak, Sözen ve Karadavut (2020), fasulyede yaş ağırlık özelliği pişme süresi ile doğru orantılı olduğunu ifade etmişlerdir. Fatahi ve ark. (2014), börülcede yaş ağırlık değerini uygulamalara göre 44.0-57.13 arasında değişim gösterdiğini tespit etmişlerdir.

Çalışmada genotip ve çeşitlerin şişme indeksi iki yıl ortalamalarına göre 2.09-2.70 arasında değişim göstermiştir. En yüksek şişme indeksi Sırma çeşidinde belirlenmiş, B1 genotipi (2.63) ile Sırma çeşidi istatistiki olarak aynı grupta yer almıştır. En düşük şişme indeksi ise B3 ve B5 genotiplerinde tespit edilmiştir. Şişme indeksi yıllara göre önemli bir farklılık göstermemiştir (Tablo 4). Şişme indeksi, su alan tohumların hacimlerinin başlangıç hacimlerine göre ne kadar arttığı ifade etmektedir (Elkoca ve Çınar, 2015). Börülcenin şişme indeksini Tigga ve ark. (2014), 0.339-2.557, Hamid ve ark. (2016), siyah börülcenin 0.84 , kırmızı börülcenin 1.15 , Verma ve ark. (2019) ise, 1.11-1.86 arasında değişim gösterdiğini ifade etmişlerdir. Araştırmada elde edilen değerler ile literatürler arasındaki farklılıkların 
nedeni, çeşit ve genotiplerin genetik yapısı, yetiştirildikleri bölgenin çevre şartlarından kaynaklandığı düşünülmektedir.

Börülce genotip ve çeşitlerinin geometrik ortalama çapları 6.51-7.54 mm arasında değişim göstermiştir. En yüksek geometrik ortalama çap Sırma çeşidinde belirlenirken, B1, B2 ve B4 genotipleri ile Amazon çeşidi Sırma çeşidi ile aynı istatistiki grupta yer almışlardır. En düşük geometrik ortalama çap ise B5 genoti- pinde tespit edilmiştir. Diğer taraftan geometrik ortalama çap 2019 yılına göre 2020 yılının $(7.28 \mathrm{~mm})$ daha yüksek olduğu tespit edilmiştir (Tablo 4). Nitekim börülcenin geometrik ortalama çapını Kaptso ve ark. (2008), $6.4 \mathrm{~mm}$, Kabaş ve ark. (2007), $7.16 \mathrm{~mm}$, Twumasi-Ankra (2015), 5.27-5.90 mm, Hamid ve ark. (2016), kırmızı börülcenin 5.72 mm, siyah börülcenin ise $5.07 \mathrm{~mm}$ olarak tespit etmişlerdir. Çalışmada elde edilen geometrik ortalama çap değerleri, incelenen literatürler ile uyum içerisindedir.

Tablo 4. Börülce çeşit ve genotiplerinin yaş ağırlık, şişme indeksi ve geometrik ortalama çapa ilişkin ortalama değerler

\begin{tabular}{cccccccccc}
\hline Genotip/ & \multicolumn{3}{c}{ Yaş Ağırlık (g) } & \multicolumn{4}{c}{ Şişme Indeksi } & \multicolumn{3}{c}{ Geometrik Ortalama Çap(mm) } \\
\cline { 2 - 10 } Çeşitler & $\mathbf{2 0 1 9}$ & $\mathbf{2 0 2 0}$ & Ort. & $\mathbf{2 0 1 9}$ & $\mathbf{2 0 2 0}$ & Ort. & $\mathbf{2 0 1 9}$ & $\mathbf{2 0 2 0}$ & Ort. \\
\hline B1 & 45.71 & 45.59 & $45.65 \mathrm{a}$ & 2.58 & 2.69 & $2.63 \mathrm{ab}$ & 7.33 & 7.35 & $7.34 \mathrm{a}$ \\
B2 & 44.97 & 43.55 & $44.26 \mathrm{a}$ & 2.45 & 2.58 & $2.52 \mathrm{~b}$ & 7.16 & 7.35 & $7.26 \mathrm{ab}$ \\
B3 & 42.77 & 43.36 & $43.06 \mathrm{a}$ & 2.11 & 2.13 & $2.12 \mathrm{~d}$ & 6.68 & 7.10 & $6.89 \mathrm{bc}$ \\
B4 & 45.32 & 44.80 & $45.06 \mathrm{a}$ & 2.30 & 2.25 & $2.28 \mathrm{c}$ & 7.02 & 7.22 & $7.12 \mathrm{ab}$ \\
B5 & 25.44 & 24.64 & $25.04 \mathrm{~b}$ & 2.10 & 2.09 & $2.09 \mathrm{~d}$ & 6.14 & 6.89 & $6.51 \mathrm{c}$ \\
Amazon & 42.79 & 43.82 & $43.31 \mathrm{a}$ & 2.43 & 2.52 & $2.48 \mathrm{~b}$ & 7.04 & 7.28 & $7.16 \mathrm{ab}$ \\
Sırma & 46.99 & 45.05 & $46.02 \mathrm{a}$ & 2.65 & 2.74 & $2.70 \mathrm{a}$ & 7.32 & 7.75 & $7.54 \mathrm{a}$ \\
\hline Ort. & 42.00 & 41.54 & & 2.37 & 2.43 & & $6.96 \mathrm{~b}$ & $7.28 \mathrm{a}$ & \\
\hline
\end{tabular}

B1: Adana, B2:İzmir, B3:Mersin, B4:Mersin/Mut, B5:Isparta

*Aynı harflere sahip ortalamalar arasında istatistiksel farklılık bulunmamaktadır.

Küresellik, aynı hacme sahip bir küreye göre bir katı şeklinin ifadesidir (Omobuwajo ve ark., 1999). İki yıl ortalamalarına göre börülce genotip ve çeşitlerinin küresellik değeri 0.73-0.79 arasında değişim gösterdiği belirlenmiştir. Genotip ve çeşitler içerisinde en yüksek küresellik değeri B5 genotipinde ve Sırma çeşidinde (0.78) tespit edilmiştir. En düşük küresellik değeri ise B3 ve B4 genotipleri sahip olmuştur (Tablo 5).Nitekim,çalışmada elde edilen bu değerler fasulye tohumu için bildirilen 0.60'dan daha yüksek (Altuntaş ve Demirtola, 2007), ancak soya (Soyoye ve ark., 2018) ve maş fasulyesi (Dahiya ve ark., 2015) için rapor edilen değerlerden(sırasıyla 0.81, 0.82) daha düşük olduğu tespit edilmiştir. Faleye ve ark. (2013), börülce çeşitlerinin küresellik değerlerini 0.69-0.78 arasında değişim gösterdiğini ve börülcenin, tahıllara benzer olarak eşdeğer bir küre olarak incelenebileceğini ifade etmişlerdir. Börülce tohumunun fasulye tohumu gibi kayması yerine yuvarlanması beklenmekte olup, bu özellik tahıl işleme makinelerinin tasarımında oldukça önem arz etmektedir (Omobuwajo ve ark., 1999; Olukunle ve Atere, 2001).

Tohum hacmi, işleme süreçleri için önemli olup, diğer farklı parametreleri hesaplamaya yardımcı olan bir özelliktir (Dahiya ve ark., 2015). Börülce genotip ve çeşitlerinin iki yıllık tohum hacimleri ortalaması en yüksek Sırma çeşidinde $\left(233.67 \mathrm{~mm}^{3}\right)$, en düşük ise B5 genotipinde $\left(155.12 \mathrm{~mm}^{3}\right)$ tespit edilmiştir. Ayrıca, tohum hacmi 2019 yılına göre 2020 yılında daha fazla olduğu belirlenmiştir. Çalışmanın yapıldığı her iki yılında da Sırma çeşidi en yüksek tohum hacmine sahip olurken, en düşük tohum hacmi ise B5 genotipinde tespit edilmiştir (Tablo 5).Börülcenin tohum hacmini Kaptso ve ark. (2008), $110 \mathrm{~mm}^{3}$, Kabaş ve ark. (2007), 150$210 \mathrm{~mm}^{3}$ ve Twumasi-Ankra (2015), 183.78-213.02 $\mathrm{mm}^{3}$ arasında değişim gösterdiğini ifade etmişlerdir. Yapılan çalışmalar göz önüne alındığında, elde edilen veriler ile uyum içerisindedir. 
Tablo 5. Börülce çeşit ve genotiplerinin küresellik, hacim ve yüzey alanına ilişkin ortalama değerler

\begin{tabular}{cccccccccc}
\hline $\begin{array}{c}\text { Geno- } \\
\text { tip/Çe- }\end{array}$ & \multicolumn{3}{c}{ Küresellik } & \multicolumn{3}{c}{ Tohum Hacmi $\left.\mathbf{( m m}^{\mathbf{3}}\right)$} & \multicolumn{3}{c}{ Yüzey Alanı $\left(\mathbf{m m}^{2}\right)$} \\
\cline { 2 - 10 } şitler & $\mathbf{2 0 1 9}$ & $\mathbf{2 0 2 0}$ & Ort. & $\mathbf{2 0 1 9}$ & $\mathbf{2 0 2 0}$ & Ort. & $\mathbf{2 0 1 9}$ & $\mathbf{2 0 2 0}$ & Ort. \\
\hline B1 & 0.73 & 0.74 & $0.74 \mathrm{bc}$ & $205.84 \mathrm{~b}$ & $208.98 \mathrm{~b}$ & $207.41 \mathrm{~b}$ & 168.67 & 169.94 & $169.31 \mathrm{a}^{*}$ \\
B2 & 0.74 & 0.74 & $0.74 \mathrm{bc}$ & $192.30 \mathrm{c}$ & $208.23 \mathrm{~b}$ & $200.26 \mathrm{bc}$ & 161.05 & 166.76 & $163.90 \mathrm{a}$ \\
B3 & 0.74 & 0.72 & $0.73 \mathrm{c}$ & $171.23 \mathrm{e}$ & $174.93 \mathrm{~d}$ & $173.08 \mathrm{e}$ & 140.05 & 149.08 & $144.56 \mathrm{~b}$ \\
B4 & 0.74 & 0.71 & $0.73 \mathrm{c}$ & $182.69 \mathrm{~d}$ & $196.79 \mathrm{c}$ & $189.74 \mathrm{~d}$ & 155.00 & 163.57 & $159.29 \mathrm{ab}$ \\
B5 & 0.78 & 0.80 & $0.79 \mathrm{a}$ & $155.94 \mathrm{f}$ & $154.30 \mathrm{e}$ & $155.12 \mathrm{f}$ & 118.27 & 122.89 & $120.58 \mathrm{c}$ \\
Amazon & 0.75 & 0.73 & $0.74 \mathrm{bc}$ & $183.24 \mathrm{~d}$ & $202.88 \mathrm{bc}$ & $193.06 \mathrm{~cd}$ & 155.89 & 169.78 & $162.84 \mathrm{a}$ \\
Sirma & 0.77 & 0.78 & $0.78 \mathrm{ab}$ & $224.71 \mathrm{a}$ & $242.63 \mathrm{a}$ & $233.67 \mathrm{a}$ & 168.56 & 175.90 & $172.23 \mathrm{a}$ \\
\hline Ort. & 0.75 & 0.74 & & $187.99 \mathrm{a}$ & $198.39 \mathrm{~b}$ & & $152.5 \mathrm{~b}$ & $159.7 \mathrm{a}$ & \\
\hline
\end{tabular}

B1: Adana, B2:İzmir, B3:Mersin, B4:Mersin/Mut, B5:Isparta

Aynı harflere sahip ortalamalar arasında istatistiksel farklılık bulunmamaktadır

Börülce genotip ve çeşitlerinin ortalama yüzey alanı değerleri 120.58-172.23 $\mathrm{mm}^{2}$ arasında değişim göstermiştir. En yüksek yüzey alanı Sırma çeşidinde, en düşük ise B5 genotipinde tespit edilmiştir. En yüksek yüzey alanına sahip olan Sırma çeşidi ile Amazon çeşidi, $\mathrm{B} 1, \mathrm{~B} 2$ ve B4 genotipleri aynı istatistiki grupta yer almışlar. Yüzey alanı 2020 yılına $\left(159.7 \mathrm{~mm}^{2}\right)$ göre 2019 yılından (152.5 mm²) daha fazla olduğu belirlenmiştir (Tablo 5). Ayrıca, börülce çeşit ve genotiplerinin yüzey alanı, kuru ağırlık değerleri ile paralellik gösterdiği tespit edilmiştir. Nitekim, Dumanoğlu ve ark. (2019), bin dane ağırlığı ile yüzey alanı arasında olumlu ve önemli bir ilişki olduğunu ifade etmişlerdir. İncelenen literatür çalışmalarına göre, börülcenin yüzey alanını Kaptso ve ark. (2008), $129 \mathrm{~mm}^{2}$, Kabaş ve ark. (2007), 145.98$185.21 \mathrm{~mm}^{2}$, Faleye ve ark. (2013), 103.96-168.45 $\mathrm{mm}^{2}$ arasında değişim gösterdiğini bildirmişlerdir.

\section{SONUÇ}

Bu çalışmada, farklı yılların börülce genotip ile çeşitlerinin fiziksel ve teknolojik özellikleri üzerine etkileri belirlenmiştir. İncelenen özellikler üzerine yıllar (bakla uzunluğu, bakla genişliği, tohum uzunluğu, şişme indeksi, geometrik ortalama çap, tohum hacmi ve yüzey alanı) ve genotipler arasında önemli farklılıklar ortaya çıktığı tespit edilmiştir. Genotip ve çeşitlerin iki yıl ortalaması bakımından değerlendirildiğinde genel olarak incelenen özelliklerde B1 genotipi ile Sırma çeşidi ön plana çıkmaktadır. Ayrıca, B1 genotipinin tescilli çeşitlere yakın hatta bazen daha iyi değerler aldığı tespit edilmiştir. İncelenen fiziksel ve teknolojik özellikler mekanizasyon ve tüketicilerin tercihinde önem arz etmesi sebebiyle B1 genotipinin (Adana) çeşit geliştirmede ön plana çıkacağı öngörülmektedir.

\section{TEŞEKKÜR}

Çalışmada kullanılan tescilli çeşitlerin teminde yardımlarını esirgemeyen Prof. Dr. Hatice BOZOĞLU ve Prof. Dr. Erkut PEKŞEN'e teşekkür ederiz.

\section{KAYNAKLAR}

Alayande, L. B., Mustapha, K.B., Dabak, J. D., Ubom, G.A. (2012). Comparison of nutritionalvalues of brown and white beans in Jos North Local Government markets. African Journal of Biotechnology, 11: 10135-10140.

Altuntas, E., Demirtola, H. (2007). Effect of moisturecontent on physical properties of some grain legume seeds. New Zealand Journal of Crop and Horticultural Science, 35(4): 423-433.

TTSM (2001). Tarımsal değerleri ölçme denemeleri teknik talimatı. Ankara, $46 \mathrm{p}$.

Avanza, M., Acevedo, B., Chaves, M., Añón, M. (2013). Nutritionaland anti-nutritional components of four cowpea varieties under thermal treatments: Principal component analysis. Food Science and Technology, 51: 148-157.

Aydoğan, S., Şahin, M., Akçacık, A. G., Hamzaoğlu, S., Demir, B., Güçbilmez, Ç. M., Keleş, R. (2020). Konya koşullarında bazı kuru fasulye genotiplerinin kalite özelliklerinin belirlenmesi. Akademik Ziraat Dergisi, 9(2): 259-270.

Bart-Plange, A., Dzisi, K. A., Ampah, J. (2012). Effect of drying on selected physical properties of "Asontem" cowpea variety. International Scholarly Research Notices, 496026; DOI: 10.5402/2012/496026

Başaran, U., Ayan, I., Acar, Z., Mut, H.,Asci, O. O. (2011). Seed yield and agronomic parameters of cowpea (Vigna unguiculata L.) genotypes grown in the Black Sea region of Turkey. African Journal of Biotechnology, 10(62): 13461-13464.

Binici, A.B., Bozokalfa, M.K. 2020. Yerel Börülce (Vigna unguiculata (L.) Walp.) populasyonlarının bakla ve danelerinin agronomik özelliklerinin belirlenmesi. Ege Üniversitesi Ziraat Fakültesi Dergisi, Özel Sayı: 51-60.

Bozokalfa, M. K., Sürmeli, F. (2019). Teksel seleksiyon yoluyla elde edilen börülce (Vigna unguiculata L. Walp) genotiplerininagronomik özelliklerinin belirlenmesi. Ege Üniversitesi Ziraat Fakültesi Dergisi, 56(4): 497-504.

Çalışkan, S., Aytekin, R. İ., Yağız, A. K., Yavuz, C. (2018). Effect of full and limited irrigation treatments on seed quality of some common bean cultivars (Phaseolus vulgaris L.). Turkish Journal of Agriculture-Food Science and Technology, 6(12): 1853-1859.

Dahiya, P. K., Linnemann, A. R., Van Boekel, M. A. J. S., Khetarpaul, N., Grewal, R. B.,Nout, M. J. R. (2015). Mung 
bean: technological and nutritional potential. Critical Reviews in Food Science and Nutrition, 55(5): 670-688.

Davies R.M. (2010). Some physical properties of Arigo seed. International Agrophysics, 24:89-92.

Dumanoğlu, Z., Özkan, Ş. S., Topçu, G. D. (2019). İtalyan çimi (Lolium multiflorum L.) çeşitlerine ait tohumların bazı fiziksel özelliklerinin belirlenmesi. Uluslararası Tarım ve Yaban Hayatı Bilimleri Dergisi, 5(2): 292-298.

Elkoca, E., Çınar, T. (2015). Bazı kuru fasulye (Phaseolus vulgaris L.) çeşit ve hatlarının Erzurum ekolojik koşullarına adaptasyonu, tarımsal ve kalite özellikleri. Anadolu Tarım Bilimleri Dergisi, 30(2): 141-153.

Faleye, T., Atere, O. A., Oladipo, O. N., Agaja, M. O. (2013). Determination of some physical and mechanical properties of some cowpea varieties. African Journal of Agricultural Research, 8(49): 6485-6487.

FAO (2019). Plant production statistics..http://www.fao.org/faostat/en/\#data/QC (Erişim Tarihi: 01.09.2021)

Fatahi, E., Mobasser, H. R., Akbarian, M. M. (2014). Effect of organic fertilizer on wet weight, dry weight and number of leaves in cowpea. Journal of Applied Sciences, 3(4): 440-443.

Futuless, K. N., Bake, I. D., Tizhe, W. (2010). Effect of Sowing date on yield and yield components of cowpea (Vigna unguiculata (I.) walp) in Mubi North local government area, Adamawa State, Nigeria. New York Science Journal, 3(11): 98-102.

Goenaga, R., Ayala, T., Quiles, A. (2013). Yield performance of cowpea plant introductions grown in Calcareous soils. Hort Technology, 23(2): 247-251.

Hamid, S., Muzaffar, S., Wani, I. A., Masoodi, F. A., Bhat, M. M. (2016). Physical and cooking characteristics of two cowpea cultivars grown in temperate Indian climate. Journal of the Saudi Society of Agricultural Sciences, 15(2): 127-134.

Henshaw, F. O. (2008). Varietal differences in physical characteristics and proximate composition of cowpea (Vigna unguiculata). World Journal of Agricultural Sciences, 4(3): 302-306

Kabaş, O., Yilmaz, E., Ozmerzi, A., Akinci, İ. (2007). Some physical and nutritional properties of cowpea seed (Vigna sinensis L.). Journal of Food Engineering, 79(4): 14051409.

Kaptso, K. G., Njintang, Y. N., Komnek, A. E., Hounhouigan, J., Scher, J., Mbofung, C. M. F. (2008). Physical properties and rehydration kinetics of two varieties of cowpea (Vigna unguiculata) and bambara groundnuts (Voandzeia subterranea) seeds. Journal of Food Engineering, 86(1): 91-99.

Karaman, R. (2019). Maş fasulyesi (Vigna radiata Wilczek) genotiplerinin/yerel popülasyonlarının Isparta koşullarında fenolojik, morfolojik, agronomik ve bazı teknolojik özellikler yönünden karakterizasyonu. Doktora tezi, Süleyman Demirel Üniversitesi, Fen Bilimleri Enstitüsü, Isparta.

Khan, A., Barı, A., Khan, S., Shah, N. H., Zada, I. (2010). Performance of cowpea genotypes at higher altitude of NWFP. Pakistan Journal of Botany,42(4): 2291-2296.

Kınacı, G., Akın, R., Kınacı, E. (2008) Farklı sulama rejimlerinin kuru fasulyenin (Phaseolus vulgaris L.) fiziksel kalite özellikleri üzerine etkileri. Celal Bayar University Journal of Science, 4(2): 179-186.

Kır, A., Tan, A., Ay, N., Korkmaz, N., Gündüz, M. (2015). Ege ve Akdeniz Bölgesi (Vigna unguiculata (L.) Walp) yerel çeşitlerinin agro- morfolojik karakterizasyonu. Anadolu Journal of $A A R I, 25(2)$ : 1-3.

Kiani Deh Kiani, M., Minaei, S., Maghsoudi, H., Ghasemi Varnamkhasti, M. (2008). Moisture dependent physical properties of redbean (Phaseolus vulgaris $\mathrm{L}$ ) grains. International Agrophysics, 22: 231-237.

Mendonça, M. S. D., Beber, P. M., Nascimento, F. S. S. D., Santos, V. B. D.,Marinho, J. T. (2018). Importance and correlations of characters for cowpea diversity in traditional varieties 1. Revista Ciência Agronômica, 49: 267274.

Molosiwa, O. O., Gwafila, C., Makore, J., Chite, S. M. (2016). Phenotypic variation in cowpea (Vigna unguiculata [L.] Walp.) germplasm collection from Botswana. International Journal of Biodiversity and Conservation, 8(7): 153163.

Moses, D. R., Zibokere, D. S. (2011). Effect of moisture content on some physical and mechanical properties of three varieties of cowpea (Vigna unguiculata (L) Walp). Agricultural Engineering International: CIGR Journal, 13(1):18.

Olukunle, O. J., Atere, A.O. (2001). Mechanical properties of (Tubers) Cocoyam and Potato. J. Advan. Agric. Eng., 1:34-40.

Ombakho, G. A., Tyagi, A. P., Pathak, R. S. (1987). Inheritance of resistance to the cowpea aphid in cowpea. Theoretical and Applied Genetics, 74(6): 817-819.

Omobuwajo, O. T., Akande, A. E., Sanni, A. L. (1999). Selected physical, mechanical and aerodynamic properties African Breadfruit (Treculia africana) seeds. Journal of Food Engineering, 40: 241-244.

Özlü, R.R., Güner, M. (2016). Determination of the physical properties of the canola seeds in different moisture content levels. Gaziosmanpașa Üniversitesi Ziraat Fakültesi Dergisi, 33(Ek Sayi): 10-24.

Öztürk, D. (2010). Ordu ekolojik koşullarında yetiştirilecek börülce (Vigna sinensis L.) ekotiplerinin bazı fizyolojik ve morfolojik özellikleri ile verim ve verim öğelerinin belirlenmesi. Yüksek Lisans Tezi, Ordu Üniversitesi, Fen Bilimleri Enstitüsü, Ordu.

Öztokat, C., Demir, İ. (2010). The comparison of some cowpea populations according to their growth, yield and seed quality. In $2^{\text {nd }}$ International Symposium on Sustainable Development, 8-9.

Pekşen, E., Pekşen, A., Bozoglu, H., Gulumser, A. (2000). Değişik börülce (Vigna unguiculata (L.) Walp.) genotiplerinde bazi tohum özelliklerinin belirlenmesi. Journal of the Faculty of Agriculture, 15(2): 65-72

Pekşen E, Artık C. (2004). Comparison of some cowpea (Vigna unguiculata L. Walp) genotypes from Turkey for seed yield and yield related characters. Journal of Agronomy, 3(2):137-140.

Rivas, R., Falcão, H.M., Ribeiro, R.V., Machado, E.C., Pimentel, C., Santos, M.G. (2016). Drought tolerance in cowpea species is driven by less sensitivity of leaf gas 
Exchange to water deficit and rapid recovery of photosynthesis after rehydration. South African Journal of Botany, 103: 101-107.

Sert, H., Ceylan, E. (2012). Hatay ili ekolojik şartlarında börülce (Vigna unguicalata (I.) savi) çeşitlerinin tane verimi ve bazı tarımsal özellikleri üzerine farklı bitki sıklıklarının etkileri. Selcuk Journal of Agriculture and Food Sciences, 26(1): 34-43.

Salisbury, F. B., Ross, C. W. (1992). Plant Physiology. Wadsworth Pub. Com., California.

Soyoye, B. O., Ademosun, O. C., Agbetoye, L. A. (2018). Determination of some physical and mechanical properties of soybean and maize in relation to planter design. Agricultural Engineering International: CIGR Journal, 20(1): 81-89.

Sözen, Ö., Karadavut, U. (2020). Farklı lokasyonlarda yetiştirilen kuru fasulye genotiplerinin (Phaseolus vulgaris L.) bazı kalite özelliklerinin belirlenmesi üzerine bir araştırma. Türk Tarım ve Doğa Bilimleri Dergisi, 7(4): 12051217.

Sürmeli, F. (2017). Teksel seleksiyon yoluyla elde edilen börülce genotiplerinin agronomik özelliklerinin belirlenmesi. Yüksek Lisans Tezi, Ege Üniversitesi, Fen Bilimleri Enstitüsü, İzmir.

Şehirali, S., Özçelik, H., Yorgancılar, Ö. (1994). Kuru tane olarak tüketilen bodur fasulye gen kaynaklarının karakterizasyonu üzerinde araştırma. 1. Tarla Bitkileri Kongresi, Bitki Islahı Bildirileri 2, 25-29 Nisan, Bornova-İzmir, 134140.
Şenol, H., Alaboz, P., Demir, S., Dengiz, O. (2020). Computational intelligence applied to soil quality index using GIS and geostatistical approaches in semiarid ecosystem. Arabian Journal of Geosciences, 13(23):1-20.

Tigga, K., Dhanwani, R. K., Solanki, A., Pandey, R. (2014). Geneticvariability in cowpea (Vigna unguiculata (L.) Walp.) at Chhattisgarh Plains. Biosciences, 7(1): 983985.

Twumasi-Ankra, O. (2015). Effect of moisture on selected physical properties of "Padi-Tuya" and "Songotra" cowpe avarieties, Doctoral dissertation, A Thesis Department of Agricultural Engineering, Kwame Nkrumah University of Science and Technology.

TUIK (2019). Türkiye İstatistik Kurumu. http://www.tuik.gov.tr/itkiselapp/bitkisel.zul (Erişim Tarihi: 04.09.2021)

Ünlü, H., Padem, H. (2005). Börülce (Vigna unguiculata (L.) Walp.) çeşitlerinde farklı ekim zamanlarının sulu ve kurak koşullarda verim ve kalite özelliklerine etkisi. Süleyman Demirel Üniversitesi Fen Bilimleri Enstitüsü Dergisi, 9(3): 110-119.

Verma, A., Kushwaha, A., Kumar, A., Baghel, S. S. (2019). Physico-chemical properties and nutritional composition of improved varieties of grain cowpea grown in Pantnagar. Journal of Pharmacognosy and Phytochemistry, 334-338.

Vural, H., Eşiyok, D., Duman, İ. (2000). Kültür sebzeleri (sebze yetiştirme). Ege Üniversitesi Basım Evi, Bornova, Izmir. 